\title{
Prevalence of Postpartum Onset of Disease within Patients with Graves' Disease of Child-Bearing Age
}

\author{
Hisato TADA, Yoh HidAKA, Eriko TSURUTA, Taku KASHIWAI, \\ Haruo TAMAKI, Yoshinori IWATANI and NobUyuki AMINO \\ Department of Laboratory Medicine, Osaka University Medical School, \\ Osaka 565, Japan
}

\begin{abstract}
To assess the prevalence of postpartum onset of disease among the patients with Graves' disease, we performed a retrospective examination of 289 consecutive female patients with Graves' disease who attended our thyroid clinic. Of these patients, 92 were female of child-bearing age (20-39 y.o.) who have had one or more deliveries, and at least 37 patients revealed clear evidences of postpartum onset of the disease. That is, at least $40 \%$ of Graves' patients of 20-39 y.o. developed their disease during the postpartum period.
\end{abstract}

Key words: Graves' disease, Postpartum onset.

(Endocrine Journal 41: 325-327, 1994)

IT IS WELL known that pregnancy markedly influences the clinical course of autoimmune thyroid diseases. Besides aggravating thyroid diseases, various kinds of autoimmune thyroid dysfunctions are newly observed after delivery. Thus, thyroid dysfunction is found in 5.5-7.1 percent of postpartum women in the general population [1-3]. Among those who reveal thyroid dysfunction after delivery, some will develop Graves' disease. This postpartum onset of Graves' disease seems to be a common form of development of the disease. Historically, the first case of Graves' disease seen by C. H. Parry in $\mathbf{1 7 8 6}$ was that of postpartum onset [4]. One of 3 female patients reported by Basedow in 1840 was also a case of postpartum onset [5].

There are few data for Japanese, but a considerable proportion of the Graves' disease cases may be considered to be of postpartum onset. To settle this, we performed a retrospective examination of the 289 consecutive female patients with Graves'

Received: August 30, 1993

Accepted: February 18, 1994

Correspondence to: Dr. Hisato TADA, Department of Laboratory Medicine, Osaka University School of Medicine, 2-2 Yamada-oka, Suita, Osaka 565, Japan disease who attended our thyroid clinic, in whom the prevalence of postpartum onset among female patients of child-bearing age was $40 \%$.

\section{Subjects and Methods}

We examined 289 consecutive female patients who attended our thyroid clinic by carefully reviewing their history. Graves' disease was diagnosed by an increase in serum free thyroxine (FT4) for more than three months, suppressed serum TSH, positive TSH-binding inhibitory immunoglobulins (TBII) and/or high radioiodine uptake, as well as the thyrotoxic clinical symptoms. Postpartum destructive thyrotoxicosis was ruled out by observing the clinical course in which thyrotoxicosis was not transient nor followed by hypothyroidism or by directly demonstrating high radioactive iodine uptake. When the patients developed thyrotoxic symptoms within one year after delivery, we regarded these as of postpartum onset. Variations in laboratory test results after delivery continue for more than 6 months, and although most patients develop their disease within 3 to 6 months after delivery, some develop the dis- 
Table 1. Age distribution and prevalence of postpartum onset in patients with Graves' disease

\begin{tabular}{|c|c|c|c|c|c|c|}
\hline \multirow{4}{*}{289} & \multicolumn{2}{|l|}{ Age } & \multicolumn{2}{|l|}{ Delivery } & \multicolumn{2}{|l|}{ Onset } \\
\hline & $<$ Twenty & 26 & & & & \\
\hline & $\geqslant$ Forty & 89 & & & & \\
\hline & Twenty Forty & 174 & None & 82 & & \\
\hline & & & One or more & 92 & Postpartum & 37 \\
\hline & & & & & Unclear & 55 \\
\hline
\end{tabular}

Data indicate number of patients.

ease later.

The measurements of serum FT4, TSH, TBII were performed with commercially available kits (FT4: Free T4 kit, Eiken Immunochemical Laboratory, Tokyo; TSH: SPAC-S TSH kit, Daiichi Radioisotope Laboratories, Tokyo; TBII: Baxter TRAb, Baxter Co., Tokyo, Japan). The normal reference values in our laboratory are as follows: FT4, 0.8-1.4 $\mathrm{ng} / \mathrm{dl}$; FT3, TSH, 0.3-5.6 mU/l, TBII, $<10 \%$. Radioactive iodine uptake was measured at $6 \mathrm{~h}$ after the oral administration of $185 \mathrm{kBq}$ of $\mathrm{Na}\left[{ }^{123} \mathrm{I}\right]$.

\section{Results}

Among 289 consecutive female patients, 174 were of child-bearing age (20-39 y.o.). Ninety-two had experienced one or more deliveries. By carefully reviewing their history, we found in 37 patients reliable evidence of postpartum onset, although onset in the other 55 were not (unclear, obviously not postpartum or possibly postpartum but not definite) (Table 1). Thus, at least 40 percent $(37 / 92)$ of patients developed the disease after delivery.

\section{Discussion}

The present study clarified that in the onset of
Graves' disease at least $40 \%$ of the female patients of child-bearing age develop their disease after delivery. This is comparable to the report by Jansson et al. of Swedish patients with Graves' disease (31 percent showed postpartum onset) [6]. These patients would be diagnosed at the time of, or more preferably before, their onset, if high-risk women were screened in early-pregnancy and followed up during the postpartum period. Because it was estimated that the prevalence of new onset of Graves' disease among postpartum women in the general population is 0.15 percent in a previous report [7] and more $(1 / 200)$ in a recent study by us (manuscript in preparation), the screening tests could justify their costs when the efficiency of the screening procedures is sufficiently high, and they would provide much benefit in the patient management and in improving the quality of life.

\section{Acknowledgements}

This study is supported by grants from Grant-in Aid Scientific Research (to N.A.; No. 05454584) from the Ministry of Education, Science and Culture of Japan; the Intractable Disease Division of Public Health Bureau, Ministry of Health and Welfare and the Foundation for Total Health Promotion.

\section{References}

1. Amino $\mathrm{N}$, Mori $\mathrm{H}$, Iwatani $\mathrm{Y}$, Tanizawa $\mathrm{O}$, Kawashima M, Tsuge I, Ibaragi K, Kumahara $Y$, Miyai K (1982) High prevalence of transient postpartum thyrotoxicosis and hypothyroidism. N Engl J Med 306: 849-852.
2. Jansson R, Bernander S, Karlsson A, Zelvin $K$, Nilsson G (1984) Autoimmune thyroid dysfunction in the postpartum period. J Clin Endocrinol Metab 58: 681-687.

3. Walfish P, Chan J (1985) Postpartum hyperthyroid- 
ism. Clin Endocrinol Metab 14: 417-447.

4. Parry C (1825) Enlargement of the thyroid gland in connection with enlargement of palpitation of the heart. In: Collection from the Unpublished Papers of the Late Caleb Hilliel Parry. London, 111.

5. Von Basedow K (1840) Exophthalmos durch Hypertrophie des Zellgewebes in der Augenhöhle. Wochenschr Heilk 6: 197-204, 220-228.

6. Jansson R, Dahlberg PA, Winza B, Meirik O,
Säfwenberg J, Karlsson A (1987) The postpartum period constitutes an important risk for the development of clinical Graves' disease in young women. Acta Endocrinol (Copenh) 116: 321-325.

7. Amino N, Iwatani Y, Tamaki H (1985) Postpartum autoimmune thyroid syndromes. In: Walfish PG, Wall JR, Volpé R (eds) Autoimmunity and the Thyroid. Academic Press Inc., Orlando, 289-314. 